\title{
Nosotros los académicos. Narrativas identitarias y autodefinición en la universidad actual*
}

Recibido: 30 de octubre de 2014 | Aceptado: 15 de septiembre de 2015

\author{
CARLA FARDELla ${ }^{* *}$ \\ VICENTE SISTO ${ }^{* * *}$ \\ FELIPE JIMÉNEZ ${ }^{* * * *}$ \\ Escuela de Psicología. Pontificia Universidad Católica de Valparaíso
}

doi :10.11144/Javeriana.upsy14-5.nani

Para citar este artículo: Fardella, C., Sisto, V., \& Jiménez, F. (2015). Nosotros los académicos. Narrativas identitarias y autodefinición en la universidad actual. Universitas Psychologica, 14(5), 1625-1636. http://dx.doi.org/10.11144/Javeriana.upsy14-5.nani

* Artículo de investigación financiado por ConicytFondecyt Nr. 3150374 Y Fondecyt Nr.1151209

** Avenida El Bosque 1290, Viña del Mar, Chile. Correo electrónico: fardellacarla@hotmail.com;

**** Correo electrónico: vicente.sisto@ucv.cl

***** Correo electrónico: felipe.jimenez@ucv.cl

\section{RESUMEN}

Las transformaciones del espacio universitario a partir de los años ochenta, en Chile, revelan el ascenso de formas managerialistas de organizar la universidad y el trabajo académico. El nuevo managment, orientado por lógicas de eficiencia y mercado, promueve una cultura laboral de rendición de cuentas y, en consecuencia, una reconfiguración de las identidades académicas llamadas a adscribirse a este nuevo modelo de universidad. Este artículo presenta una investigación cualitativa realizada en Chile con veinte académicos de planta en torno a su identidad laboral. A partir del análisis de contenido — discursivamente orientado- de veinte entrevistas, se presentan como resultado dos ejes en torno a los cuales se organizan las narrativas identitarias de los académicos, mostrando los efectos para la autodefinición de este grupo y la ética del trabajo académico.

\section{Palabras clave}

trabajo académico; capitalismo académico; identidades académicas

\section{A B S T R A C T}

The transformations of the university space from the eighties reveals the rise of managerialist ways to organize the university and its workforce, fostering a culture of accountability and plurality of tasks such as research, guided by the logic of efficiency and market movements. Such claims therefore imply the existence of reconfigurations in academic work identity. Drawing on focused interviews with 20 academics, the article shows two axes around which the narrative identities of academics are organized and what are its effects on self-definition of the group and the ethics of academic work. Keywords academic work; entrepreneurial university; academic identities 


\section{Introducción}

Chile constituye un ejemplo de implementación de reformas neoliberales en la educación superior (Germano, 2001), en tanto ha abierto "la educación superior al libre mercado y a los procesos de privatización, con la explícita intención de convertir toda institución superior en una empresa privada y autofinanciada" (Austin, 1998 citado en Germano, 2001, p. 232). Es así como, durante las últimas tres décadas, las universidades tradicionales chilenas, en tanto organizaciones laborales y sociales, han experimentado profundas transformaciones orientadas por nuevas lógicas de gestión de lo público (Anderson, 2008; Callinicos, 2006; Gill, 2009; Slaughter \& Leslie, 1997; 2001; Slaughter \& Rhoades, 2004). La nueva gestión pública o New Public Managment (NPM), habla de un espíritu empresarial privado que intenta reanimar al Estado, conminándolo a dejar atrás la pesada burocracia e incorporarse a la eficiencia y agilidad del mercado. El NPM es la técnica en la que se concreta la gestión pública de un Estado neoliberal.

De esta forma, la institucionalización del modelo neoliberal imprime al Estado y a sus universidades un nuevo espíritu. Ciertamente, Estado y universidad ven maximizada su alianza neoliberal en un contexto de capitalismo cognitivo, donde la privatización, objetivación y producción competitiva del conocimiento son fundamentales para mantener el actual orden. El NPM reorganiza el vínculo entre universidad y Estado y dota al espacio académico de un nuevo ethos. Así, se promueven acciones como la descentralización y diversificación de las fuentes de financiamiento, la incorporación del mercado como principal mecanismo regulador, la instalación de una cultura de la accountability, el desarrollo de instrumentos de acreditación y medidas de eficacia para los procesos de trabajo (Gill, 2009, Sisto, 2005; Slaughter \& Leslie, 1997, 2001). Un elemento central de esta transformación ha sido la reorganización del trabajo académico y la redefinición de su principal fuerza de trabajo: los académicos.

En efecto, la transformación de la universidad se asocia, en términos concretos, a cambios en la gestión del cuerpo académico (Brunner, 1999), lo que ha sido definido como un proceso estratégico para la transformación de la universidad (Organización para la Cooperación y el Desarrollo Económicos [OCDE], 2008). En este contexto, diversas universidades han iniciado procesos sistemáticos de perfeccionamiento del cuerpo académico: han buscado establecer sistemas eficientes de acreditación de la docencia -incentivando la investigación y producción de conocimiento-, de los académicos y de su compromiso con los proyectos institucionales y con las nuevas formas de producción. Esto se puede apreciar en diversas respuestas organizativas, desde universidades que han tendido hacia una alta flexibilización laboral y fragmentación de su cuerpo académico — conservando núcleos estables de carácter administrativo- hasta universidades que, por el contrario, han tendido a aumentar las plantas estables, implementando sistemas de evaluación, incentivo y rendición de cuentas.

De acuerdo con diversos autores, la reorganización del trabajo no solo pone en juego el desempeño de la fuerza laboral, sino también nuevas verdades, ideales y prototipos de trabajador, los cuales van cambiando en función de las formas de producción (Bauman, 1998a, 1998b; Beck, 2002; Boltanski \& Chiapello, 1999; Dubar 1991; 2000; du Gay, 2007; Gorz, 1997; Medá, 1998; Sennett, 1998). El NMP requiere subjetividades comprometidas con los nuevos ideales de autonomía, emprendimiento y polifuncionalidad, sobre todo en sociedades liberales donde, tal como señala Rose (1998), se establece la estética de la libertad y la autonomía como ejes ordenadores de lo social y lo subjetivo a través del trabajo. Dichos ideales se han impuesto a través de mecanismos de gestión concretos, favoreciendo la expansión de nuevas formas de control de las prácticas y subjetividades de los académicos (Ainsworth \& Hardy, 2008). En definitiva, la transformación de la universidad como institución pública nos habla de una nueva forma de gobierno, en la cual el Estado redefine lo público y lo privado, su relación con la producción de conocimiento y verdades y sus tácticas para producirla y hacerla circular. El capitalismo cognitivo no solo fortalece esta relación privada entre universidad y Estado, sino que establece for- 
mas mediante las cuales los académicos trabajan y se definen a sí mismos en el espacio universitario. Sin embargo, el orden neoliberal propuesto para el espacio universitario y sus sujetos no logra imponer su gramática tal como ha sido diseñada. Los numerosos dispositivos que actualmente buscan regular las subjetividades académicas no se despliegan según lo planificado, dejando ver creaciones, tensiones y tropiezos que la vitalidad de los espacios académicos provoca (Anderson, 2008; De Certeau, 1995; Gill, 2009; Knights \& Willmott, 2007; Levin \& Shaker, 2011). Este trabajo reporta los resultados de un estudio cualitativo cuyo propósito fue analizar identidades laborales de los académicos en escenarios laborales de transformación universitaria. Tal como se evidencia en los resultados, la adhesión de los académicos a los nuevos modelos de trabajo y de trabajador, propios de la reestructuración de la educación superior, es un proceso complejo que no está exento de tensiones. Si bien los nuevos escenarios sociales y políticos constituyen demandas relevantes para los trabajadores de la academia, estos últimos, en tanto sujetos reflexivos, también ejercen un trabajo de autodefinición y participan activamente de la discusión en torno a qué significa ser un académico y qué tareas se corresponden con esta identidad laboral. En este sentido, el propósito de este trabajo es contribuir a la investigación en torno a las transformaciones universitarias y su impacto en las identidades académicas. Con ello, se espera ofrecer un conjunto de claves para leer, de manera crítica, las formas en que los y académicos y académicas narran sus experiencias, conflictos identitarios y tensiones que surgen en un contexto de capitalismo académico (Slaughter \& Leslie, 1997). También busca generar diálogo y reflexión respecto de las prácticas y experiencias detrás de los procesos de producción de conocimiento académico.

Diferentes relatos sobre el quehacer académico, sobre los ideales profesionales y la ética del trabajo participan de la construcción de las identidades académicas. Estas narraciones dan cuenta de las sujeciones y desujeciones a un contexto de transformación de la universidad. Aun cuando no es intención de este trabajo dejar de mirar los vectores de fuerza que co-construyen los nuevos modelos universitarios, se ha optado por matizar estas zonas e iluminar aquellas que muestran la identidad y la universidad como espacios complejos y contradictorios, donde existen fricciones entre el ejercicio de poder al tiempo que espacios de resistencia, autonomía y autodefinición.

\section{Marco de referencia: identidad y transformaciones en el trabajo académico}

Recientemente se produjo un desplazamiento importante en la comprensión de la identidad: pasó de un modelo identitario que miraba este proceso como algo estable, unitario, privado e independiente del contexto, a un modelo que conceptualiza la identidad como un proceso constitutivamente ligado a la esfera social y relacional del cual emerge (Dubar, 1991). Producto de este desplazamiento, la noción de identidad, en tanto conformación dinámica entre lo individual y lo social, ha ido tomando fuerza. Lo individual emerge aquí como la articulación de una historia de interacciones sociales, que van generando un sentido coherente que define al sujeto y orienta su acción. Esta acción se concreta en una trama narrativa que conforma un relato de sí mismo que, a su vez, genera unidad, continuidad y coherencia respecto de un determinado contexto (Dubar, 1991; Íñiguez, 2001; Vygotski, 1979). Por ello, y a pesar de la heterogeneidad de experiencias que conforman la biografía del sujeto, es la autonarración biográfica la que genera la unidad y continuidad temporales que caracterizan la identidad (Dubar, 1991; Gubrium \& Holstein 1998; Smith \& Sparkes, 2008).

De acuerdo a Íñiguez (2001), la identidad implica una reflexividad lógica de un sujeto (individual o colectivo) que se ve a sí mismo a lo largo del tiempo. Sin embargo, este proceso de dar cuenta de sí, se constituye a partir de una serie de negociaciones con el contexto, en procesos de identificación y diferenciación con otros, aceptando y rechazando atribuciones acerca de lo que somos o debiéramos ser. Este conjunto de procesos va generando una narrativa acerca de sí que da unidad al sujeto (Dubar, 2000). 
Los estudios sociales del trabajo coinciden en señalar que la reorganización del mismo no solo pone en juego sus condiciones y el desempeño de la fuerza laboral, sino también aspectos subjetivos, identitarios y relacionales de quienes trabajan (Boltanski \& Chiapello, 1999; Gorz, 1997; Medá, 1998; Sennett, 1998; du Gay, 2007). En otras palabras, nuevas formas de organizar el trabajo conllevan nuevos prototipos profesionales y prescripciones identitarias, bajo las cuales el trabajador es obligado a leerse a sí mismo. Tal como señalan diferentes autores (Beck, 2002; Bolstanski \& Chiapello, 1999; Dubar, 2000; Gorz, 1997; Medá, 1998; Sennett, 1998), los nuevos ideales de identidad profesional se asocian al compromiso con una multiplicidad de equipos, proyectos y resultados, sin necesidad de generar lealtades a largo plazo o una evaluación continua de las alianzas que puedan beneficiar la propia trayectoria laboral, la autonomía y el incesante emprendimiento.

Un componente esencial de la lógica del NPM respecta a la acomodación del trabajo académico - y de cualquier trabajo- a las categorías de desempeño profesional actualmente dominantes en el campo del management. Es así como se desarrollan procesos de evaluación del desempeño según estándares, estrategias de pago dependientes de resultados, diversas formas de contratación flexible y promoción de determinados prototipos de profesional académico.

Mediante estos dispositivos, se instala un deber ser y hacer del académico, unas categorías de verdad que tienen por función dominar los acontecimientos y las acciones aleatorias. De todas las posibles acciones de un académico, los códigos del NPM visibilizan y promueven aquellas que tienen que ver con un modelo racional, estratégico, solitario, competitivo y emprendedor, por sobre otros como modelos como aquellos que se comprometen con el cambios social o el vínculo con los estudiantes.

En resumen, la gramática del NPM imprime principios de clasificación y ordenamiento que buscan dominar la cualidad con que las acciones académicas se volverán legibles para el sistema (Foucault, 1979). El nuevos ethos de la academia señala que no todas las formas de ser académico son válidas. De esta forma, se construyen dispositivos - jerarquizaciones de académicos, tipos de contrato, bonos por desempeño— que, mediante la exclusión y la separación (Foucault, 2008), construyen campos de lo deseable y diferencian las acciones competentes de las incompetentes. En ese proceso, una o algunas figuras identitarias se superponen en calidad de verdad, ideal y prototipo. Estas figuras no son más que una organización particular de enunciados que aparecen, en discursos hegemónicos, "a título de verdad admitida, de descripción exacta, de razonamientos fundados y premisas necesarias" (Foucault, 2002, p. 93).

Este nuevo perfil profesional establece un marco de inteligibilidad en el que el académico debe adecuar sus prácticas y releerse desde allí. Para vivirse y leerse a sí mismo como un académico ad hoc a los nuevos tiempos universitarios, se le demanda que se relate a sí mismo y a su trabajo en los términos propios de la gramática del NPM. Así, finas categorías y sutiles prescripciones funcionan como discretas formas de cooptar la identidad de los académicos. Presenciamos entonces un poder que produce verdades e ideales de profesionalismo, siendo justamente la cualidad productiva del poder, lo que hace este y la vida social se articulen (Foucault, 1979)

Diversas investigaciones han documentado el impacto de esta nueva gramática en el trabajo académico. De acuerdo con Gill (2009), las tensiones identitarias y culturales propias de la 'reingeniería' del cuerpo académico estarían asociadas a percepciones de crisis de sentido y desilusión en torno a los nuevos roles prescritos. Otros autores han documentado la pérdida de autonomía en el trabajo, sumada a las transformaciones de los aspectos éticos a través de los cuales se orienta el ser académico (Clarke, Knights, \& Jarvis, 2012). En efecto, los nuevos marcos regulatorios del trabajo académico tensionan dramáticamente los modos de ser y comprenderse a sí mismo como tal, entrando en disputa los sentidos cotidianos de la actividad, con importantes consecuencias a nivel personal —en términos de malestar y sufrimiento- (Chandler, Barry, \& Clark, 2002) "type". Se ha documentado, además, la emergencia de diversas prácticas 
de resistencia, boicot y malestar general frente a las nuevas demandas laborales (Anderson, 2008; Fardella, 2013; Levin \& Shaker, 2011; Mancebo, 2010; Sachica, 2005).

La experiencia universitaria chilena puede ser vista como un caso emblemático de transformaciones en la universidad bajo los criterios manageriales. En este contexto, es fundamental conocer cómo los académicos conviven con las nuevas categorías profesionales. ¿Cómo construyen sus identidades laborales en un contexto de transformaciones radicales? ¿Qué elaboraciones construyen para dar cuenta de sí mismos en un contexto de capitalismo académico? ¿Cómo se organiza su identidad?

\section{Método}

Para llevar a cabo este estudio, se optó por una metodología cualitativa de carácter local, específica y contextualizada (Denzin \& Lincoln, 2003; Flick, 2004). Los procedimientos de producción de conocimiento comprendidos en este trabajo son entendidos como una construcción social que se realiza con la necesaria colaboración de los participantes, y su producto persigue una contribución al diálogo social. Por ello, la producción de datos consta de veinte entrevistas activas en torno a las transformaciones de la universidad y la experiencia del trabajo académico. En las entrevistas activas, los participantes (entrevistador/a y entrevistado/a) son asumidos como sujetos que interactúan abiertamente, guiados temáticamente por una pauta flexible (Denzin, 2001; Holstein \& Gubrium, 1995). Es a través de esta actividad que logramos aproximarnos a las narraciones a través de las cuales los académicos dan cuenta de sí, donde la flexibilidad y la espontaneidad de la entrevista lleva a espacios discursivos nuevos, haciendo que entrevistados y entrevistadores se vean en la necesidad de relatar y reorganizar nuevos relatos de sí y de sus experiencias laborales (Denzin \& Lincoln, 2003).

La muestra está conformada por académicos de planta de diferentes universidades pertenecientes al Consejo de Rectores de las Universidades
Chilenas (CRUCH) de la zona central de Chile ${ }^{1}$ y representa distintos campos disciplinarios. Entrevistamos académicos provenientes de siete facultades distintas -ingeniería, medicina, psicología, sociología, trabajo social, arquitectura y pedagogía- Procuramos que hubiera igual número de hombres y mujeres y variedad en el número de años de ejercicio académico.

El análisis de datos se realizó en dos etapas. En la primera fase, el corpus de datos se codificó en función del contenido. A partir de ello, creamos unidades de significado, filtradas y reorganizadas a partir de los objetivos de la investigación. Tras la lectura sistemática de los códigos y su contexto, se buscaron patrones, temas y regularidades, así como contrastes, paradojas e irregularidades (Coffey \& Atkinson, 2003; Delamont, 1992). Posteriormente, se procedió a agrupar los códigos en categorías analíticas que dieran cuenta de los ejes narrativos organizadores de la identidad. Para ello, se siguió la orientación del análisis discursivo de narrativas identitarias (Sisto \& Fardella, 2009; Wetherell, 2007). Según esta perspectiva, el sujeto despliega versiones de sí que giran en torno a un eje que le atribuye coherencia, con el fin de responder a la presión social por dar cuenta de sí y de volverse inteligible a los otros. Esto ha sido denominado por Gubrium y Holstein (1998) como "narrativa canónica", que da cuenta no solo de los modos de inteligibilidad socialmente válidos para una posición social específica, sino también de las tensiones a las cuales está sujeta esa posición. El análisis de estos ejes se apoyó en algunos recursos del análisis de discurso pragmático (Potter \& Wetherell, 1987; Wetherell \& Potter, 1998). Quisimos abordar los ejes en torno a los cuales se construyen las versiones de sí y los efectos de estas descripciones a la hora de hablar de sí.

1 Organismo que reúne a las 25 universidades estatales y universidades privadas — denominadas tradicionales- del sistema universitario chileno . 


\section{Resultados: las narrativas canónicas en la identidad de la fuerza laboral académica}

Mediante el análisis de los datos, damos cuenta de dos ejes articuladores en torno a los cuales los participantes construyen su 'sí mismo académico': primero, el compromiso con el cambio social y, segundo, la pasión por el trabajo académico. A su vez, analizamos cuáles son los efectos de estos relatos identitarios en su posicionamiento en el actual contexto académico. Los análisis realizados serán ilustrados mediante fragmentos de entrevistas, que resultan representativos del corpus textual y de las categorías que se presentan.

\section{Identidad y compromiso con el cambio social}

El trabajo académico puede ser descrito mediante múltiples adjetivos. No obstante, en el análisis realizado, los hablantes describen frecuentemente su trabajo como un quehacer de profundo compromiso con el cambio social. A su vez, tal descripción está asociada a tareas y acciones específicas dentro de la academia. En ese sentido, si bien la academia se compone de múltiples tareas — gestión, innovación, postulación a fondos, docencia e investigación-, el compromiso con el cambio social aparece específicamente ligado a la docencia y la investigación.

De acuerdo con los relatos la investigación y sin distinción entre campos disciplinares, la investigación es planteada por los académicos como una actividad que debiese estar enfocada a colaborar con el progreso social o, en los casos que se exponen a continuación, con las políticas públicas nacionales:

El campo de las políticas públicas y el campo del mundo universitario y científico, espero puedan unirse, para que lo que investigamos pueda entonces, incidir o procurar sugerir algunos cambios en las políticas públicas ${ }^{2}$. (5:9, Sociología)

2 Convención para nominar las citas: Sistema de Transcripción Jefferson. Primer numero corresponde al Nr. de Entrevista: nr.
Es poder producir conocimiento pero con un sentido político también, no conocimiento por conocimiento, por saber más y publicar más artículos que otro (...) tiene que tener un sentido político, un sentido crítico también $(0,2)$ NECESARIAMENTE. (11:4, sociología)

Como vemos, los enunciados que describen el oficio de investigar permiten a los hablantes presentarse como sujetos que realizan tareas de investigación, pero en un sentido que trasciende la misma tarea de investigar, en tanto se espera que sean acciones con una incidencia política en la sociedad.

La docencia universitaria es descrita de una manera similar. La formación profesional emerge no solo como una tarea que ayuda al desarrollo personal del estudiante, sino que adquiere trascendencia más allá de ese ámbito: mediante la formación de profesionales con compromiso por el cambio social, la labor contribuye a la sociedad en general. Como se evidencia en los fragmentos siguientes, el desarrollo de determinadas habilidades en los estudiantes sensibilidad respecto del cambio social, reflexión y análisis crítico de la realidad — es comprendido por los académicos como una contribución articulada a la transformación social:

Lo que uno pueda hacer allí se transforma en algo estratégico, los profesionales tienen que ser actores de cambio, hacerlos reflexionar, hacerlos que adquieran una competencia que es básica: el análisis crítico de la realidad. (A4:4, medicina)

Aquí estamos formando para el ejercicio profesional (...) pero además hay una carga política donde el que se forma acá va a hacer una labor, generalmente, en sectores privados socialmente. Nuestra tarea es sensibilizarlos respecto al cambio social. (2:31, Pedagogía en educación física)

A su vez, la contribución social mediante la docencia y la investigación no solo es relatada por los hablantes como una cualidad de su trabajo, sino

de cita dentro de la entrevista, Área del conocimiento del entrevistado. 
como la principal motivación para optar por este: "Podría estar hoy día en otro lado,< y me quedé aquí porque pienso que aquí aportamos a los cambios sociales" (5:32, Arquitectura).

En suma, los relatos tienden a poner la investigación y la docencia por encima de otras tareas académicas, pues es a través de estas prácticas que los hablantes señalan poder realizar un cambio en la sociedad. Y, en efecto, el compromiso con el cambio social — que se muestra como motivación para escoger el oficio académico- les permite organizar una definición de sí como académicos. No obstante, la preeminencia con la cual emerge la contribución social a la hora de definir la labor tiene una doble función discursiva, en tanto permite al hablante describir su oficio de una manera particular a la vez que presentarse a sí mismo como un sujeto dedicado a un oficio que lo posiciona como un agente social: alguien que, a través de su oficio, toma una posición activa en el mundo, que tiene una incidencia en su entorno y la capacidad de transformar su contexto social:

Es un tema de realización personal y yo creo que uno está aquí porque tiene una misión en el sentido social y político (...) para mí tiene que ver con eso, con que uno tiene una labor más social y política, en términos de cómo contribuyes a formar la nueva generación de profesionales para tu país. (3:8, Trabajo Social)

De acuerdo con este relato, la construcción identitaria se estructura en torno a tareas de incidencia y contribución social que los hablantes desarrollan autónomamente en su trabajo. El despliegue de tales tareas es narrado, a su vez, como una serie acciones que les permite expresar sus creencias y valores más sustantivos (Soto \& Gaete, 2013). En definitiva, se trata de narrativas que dibujan un actor que toma decisiones en coherencia con sus principios y que, a través de su acción en el mundo, logra su realización personal.

Esta idea se relaciona con lo que Clarke, Knights, y Jarvis (2012) han denominado "orgullo académico", asociado a su vez con la reputación académica que se consigue a través de la creación y que se concreta en publicaciones originales y relevantes, y una enseñanza capaz de transformar al Otro. En este sentido, describirse como un agente social significa presentarse a sí mismo como profesional que decide, crea y es autor de su trabajo: "no hay alguien que me lo demande, soy yo el que está ahí, yo juego con mi libertad, y eso te hace sentir más, te hace tener más claridad en el trabajo" (7:25, Pedagogía en matemáticas).

Es importante señalar que estas versiones identitarias no se adscriben de manera absoluta a los nuevos prototipos laborales de la universidad managerialista. Por un lado, tenemos los relatos que hacen énfasis en la libertad y autonomía de la labor académica, articuladas con la individualización del trabajo y el despliegue de un modelo del yo privado que trabaja (Rose, 1998). Sin embargo, se trata también de un yo que trabaja para otros. El compromiso social bajo el cual se define el académico, obedece más bien, a construcciones históricas tradicionales de la universidad (Keenoy, 2003). Como se aprecia, se trata de narraciones que dan cuenta de posiciones identitarias que se contraponen y tensionan la demanda productivista del capitalismo académico (Slaughter \& Leslie, 1997, 2001; Slaughter \& Rhoades, 2004)

\section{Ética del quehacer académico: amor y pasión}

Este apartado reporta que la labor académica es comprendida por los entrevistados como un trabajo cargado de afectos, y que esta representación funciona como un segundo eje articulador de las narrativas que componen la identidad de estos trabajadores. En efecto, emociones como la pasión, el amor y la generosidad aparecen frecuentemente en las descripciones del oficio académico: "Hay mucho espíritu en el docente, hay mucho de corazón, podríamos llamarlo" (3:8, Trabajo Social). Este tipo de emociones no solo son empleadas como características del trabajo académico, sino como componentes esenciales de este. Como se evidencia en el siguiente fragmento, el recurso afectivo es usado en las narraciones para dar sentido a la decisión de ser académico: "Hay que añadirle pasión, amor, interés, responsabilidad, compromiso y si yo estoy aquí es porque sentí que esta 
es una casa de estudio donde se vive intensamente eso" (2:32, Pedagogía en educación física).

De esta manera, ser académico y hacer academia se construyen como efectos de determinadas emociones — pasión, amor, interés- que, por lo demás, constituyen afectos que tienden a reforzar la identidad del yo privado que abordamos en el apartado anterior.

La elección de atributos que definen el quehacer del académico, más que dar cuenta de la naturaleza del oficio, da cuenta de las características del hablante. Es decir, el ejercicio de definir la naturaleza del trabajo académico tiene efectos particulares para quien lo describe y su identidad. En este caso, el uso de un discurso emocional (Edwards, 1999) para caracterizar la actividad académica resulta particular, sobre todo por el contraste que genera en un ambiente de alta demanda de eficiencia y productivismo laboral (Callinicos, 2006; Ibarra, 2002; Jarvis \& Pratt, 2006; Slaughter \& Leslie, 1997). Se trata de un recurso retórico que permite distinguir al hablante como alguien que construye su oficio en contradicción con el contexto.

Por otra parte, las narraciones analizadas mediante el discurso emocional tienden a construir representaciones del trabajo que reflejan una profunda afinidad entre los gustos personales del hablante y los requeridos por su profesión. Esto le permite construir un "punto de encuentro simbólico" (Brown, 2006) que pareciera construir un hablante que, siguiendo sus pasiones e intereses, ha encontrado en la academia un lugar dónde desarrollarlos: "este trabajo me da tanto placer como otras esferas de la vida no laborales. Me da harto placer, sí, harto. Esto de la investigación a mí me da mucho placer" (10:1, Psicología).

De esta manera, las emociones se despliegan como recursos que componen la identidad profesional académica, en tanto permiten a los académicos narrarse a sí mismos como personas comprometidas con una pasión (Jack \& Lorbiecki, 2007; Ybema et al., 2009): "yo creo que hay una cuestión de vocación como de gusto personal, digamos. Yo aquí me siento como pez en el agua, me encanta la labor académica, sobre todo la labor de docencia" (4:3, Medicina).
Por su parte, el discurso emocional tiene importantes efectos para los académicos en el contexto del capitalismo académico. En efecto, la descripción de su trabajo como un asunto de vocación y pasión se asocia a prescripciones para la acción que se derivan de tal definición — como trabajar horas extra porque es una pasión o porque es un trabajo placentero-. Esto se ha traducido, en la mayoría de los casos, en un discurso de complicidad silenciosa con la intensificación del trabajo, propia del NPM. Como lo evidencia el siguiente fragmento, tal complicidad ha sido invisibilizada por el discurso emocional de la pasión y el compromiso: "en el fondo, es una emoción que está cargada de compromiso, de desvelo, de entregarse las 24 horas del día a esto" (2:17, Ing. Civil. Industrial).

El trabajo de Worthington y Hodgson (2005) asegura que los académicos suelen señalar que trabajan por vocación, lo que funcionaría como una fuente importante para construir su "identidad". En este sentido, la vocación se transforma en un criterio normativo para la identidad académica, pues permite a los hablantes distinguir quién es un académico genuino y quién no:

La clave está en la pasión, que es una emoción que mueve energías y que, en la medida en que nosotros infundamos esto y provoquemos en el otro, está este amor, esta pasión, eh, vamos haciendo escuela. Pero cuando uno está como midiéndose, restringiéndose, calculando todo, yo creo que estamos frente a una persona que no debe estar acá, porque esta es la universidad, la universidad es una totalidad que requiere generosidad. (2:32, Pedagogía en educación física)

El fragmento anterior ilustra la construcción de versiones alrededor del trabajo académico, donde acciones tales como medir o calcular denotan un control de la pasión por el trabajo y no representan el ethos de la academia. De esta forma, la descripción del trabajo académico como un trabajo afectivo funciona como criterio identitario de exclusión e inclusión en esta comunidad. Esto mismo se evidencia en el siguiente fragmento: 
Hay gente que no da un paso sin que no sea retribuido y reembolsado (...) Está muy legitimado eso, cada vez está más legitimado que nadie se mueve si no hay una retribución o algún intercambio material. O sea yo-yo-yo soy y yo lo elijo, explícitamente (...) estoy disponible a realizar muchas actividades $a d$ honorem. Porque sí, porque me nace, porque siento que contribuyo, porque me encanta. (4:38, Medicina)

Estos fragmentos muestran cómo se construyen relatos que cuestionan a otros académicos en tanto trabajadores que no muestran un amor incondicional por su labor. En este sentido, el trabajo condicionado y subordinado a aspectos instrumentales, como la retribución económica, configuran narraciones y personajes que encarnan lo no deseado dentro de una ética profesional académica, a la vez que posicionan al hablante como un protector de la misma. Este punto de vista fue reforzado por muchos otros participantes, quienes narraron episodios en los que la retribución económica o unas mejores condiciones laborales fueron expuestas como aspectos contrapuestos a la ética del trabajo académico: "disfrutamos mucho nuestro trabajo, en comparación con otros amigos que también pueden, en realidad, trabajar a veces por el dinero"(7:23, Pedagogía en matemáticas). "La gente que está en estas pegas no está por la plata, está porque cree en algo superior" (3:8, Trabajo Social).

Como venimos sugiriendo hace algunos párrafos, el discurso emocional y la ética académica cobran especial relevancia en un escenario de capitalismo académico. Como hemos revisado, este tipo de narraciones construye la labor académica por oposición a otras imágenes laborales contemporáneas - el interesado por el dinero vs. la generosidad; la pasión vs. el cálculo; las tareas instrumentales vs. tareas con sentido, etc.- - Los antagonismos que se construyen en estos discursos performan un eje en torno al cual se articula la identidad del académico, promulgando un determinado 'deber ser' para sí y sus colegas y prescribiendo determinado tipo de acciones e invalidando otras.

De esta manera, el hablante se presenta como un sujeto que, guiado por valores no convencionales — generosidad y compromiso- en un contexto de neomanagerialismo, elige ser académico, al tiempo que promueve ciertos criterios que lo definen como tal. Este relato de contrapuntos genera el efecto de disidencia. En otras palabras, el académico se define a sí mismo desde criterios alternativos, asociados a lo que Keenoy (2003) denomina "cultura tradicional académica", donde el amor, la pasión y el compromiso por el trabajo están relacionados con el suministro, la creación y la búsqueda del conocimiento, en detrimentro de actividades "instrumentales" — como la búsqueda de retribución económica o mejores condiciones laborales-. A esto, Harding et al. (2010) agregan que, paradójicamente, esta construcción idealizada y normativa de la identidad académica, que pareciera ser una autodefinición disidente en un contexto de capitalismo académico, constituye también un espacio íntimo, susceptible de control y explotación (Clarke, et al., 2012).

\section{Discusiones}

Este trabajo buscó identificar los ejes identitarios que permiten a los trabajadores académicos dar cuenta de sí y los efectos que tienen tales configuraciones identitarias en un contexto de capitalismo académico. Como revisamos anteriormente, el compromiso con el cambio social y el trabajo académico como un trabajo de amor y pasión operan como ejes que permiten organizar, ordenar y narrar la identidad profesional, al tiempo que seleccionar y desestimar actividades demandadas por el NPM. Tales descripciones del trabajo académico permiten a los entrevistados asumir una posición en el mundo mediante la construcción de una identidad que prescribe ciertas maneras de ser y actuar.

Como se pudo apreciar, en ambas categorías los académicos refieren el compromiso con el cambio social y el amor por su trabajo para describir tanto su oficio como a sí mismos. Ambos ejes, descritos por los hablantes por oposición a otras imágenes laborales contemporáneas, centradas en la instrumentalización del trabajo, el productivismo y eficientismo, pueden ser interpretados como criterios alternativos en la construcción de una identidad académica en un contexto de managerialismo aca- 
démico. La disidencia y la crítica, de acuerdo con Rancière (2008) y Foucault (2010), son momentos de ruptura y de reconfiguración en el escenario de lo admisible. Por ello, plantear criterios contrarios a los del sistema dominante para narrarse a sí mismo es una posibilidad de transformación de sí, pues se establecen nuevas relaciones con la 'verdad' y la subjetividad.

Sin embargo, junto a estas narraciones disidentes o desujeciones a las nuevas prescripciones de la subjetividad, encontramos también sujeciones al nuevo orden provisto para la fuerza laboral de la universidad. Ciertamente, después de esta revisión podríamos sugerir que la descripción del trabajo como una pasión es también un discurso que se ha ensamblado cómodamente con prácticas de autointensificación laboral y con condiciones laborales precarias e injustas.

Asimismo, llama la atención que el uso de la primera persona singular en los relatos de los entrevistados supera ampliamente el uso del nosotros - aunque las entrevistas se hicieron de forma individual-. En esta misma línea, encontramos que el académico se presenta a sí mismo como sujeto que se autorrealiza en el trabajo, que resuelve problemas y toma decisiones, que expresa sus intereses y su punto de vista. En síntesis, se presenta como una persona comprometida con lo social y que sigue sus pasiones. Esto invita a pensar en narrativas identitarias individualizadas (Soto \& Gaete, 2013), que no solo se adscriben a las actuales regulaciones del trabajo académico, sino que debilitan los lazos de comunidad profesional. Tal comunidad ha dependido históricamente de prácticas colectivas - como la revisión por pares y otras formas colectivas de producción de conocimiento-y de compromisos provenientes de un conjunto de creencias compartidas (Clarke, Knights, \& Jarvis, 2012). En consecuencia, los cambios que empuja la nueva cultura capitalista académica no se limitan a amenazar las identidades académicas individuales, sino también la identidad misma de la comunidad profesional.

Como se evidencia a lo largo de este trabajo, las narraciones identitarias de los académicos se adscriben a los nuevos modelos universitarios al tiempo que disienten de ellos, planteando criterios alternativos para construir sus identidades académicas. Esta tensión da cuenta de las contradicciones desde las que los académicos dan cuenta de sí, en un contexto de cambios y nuevas demandas laborales. Los relatos que presenciamos evidencian prácticas y narraciones de resistencia y de lucha por la autodefinición, así como de creación y sostenimiento de identidades académicas disidentes y alternativas. Para algunos autores (Clarke, et al., 2012), ninguna de estas formas de resistencia desafía por completo el rumbo que está tomando la universidad. Sin embargo, este trabajo sugiere que tampoco es posible afirmar que el NPM ha logrado instalarse por completo en las identidades académicas.

Nuestra misión no es resolver estas contradicciones, sino retenerlas y adentrarnos, desde allí, en el estudio de la identidad y el poder. Concretamente, argumentamos que las nuevas regulaciones del espacio universitario no han logrado colonizar por completo las identidades académicas. Simultáneamente, intentamos demostrar que la institucionalización del modelo neoliberal en las universidades convive y tropieza con fuerzas identitarias vivas, creativas y escurridizas.

Esperamos que el ejercicio de develar estas controversias contribuya a iniciar una discusión en torno al modo en que conviven el poder y la disidencia en el actual contexto académico y, más específicamente, en el difícil ejercicio de dar cuenta de sí en tanto académicos. Sin duda, el presente es un trabajo exploratorio que levanta más interrogantes de las que resuelve. Una mayor investigación en torno a estas problemáticas ayudará a evaluar las consecuencias de estas microprácticas de resistencia, la manera en que conviven con estos nuevos modelos de trabajo universitario y su posible variabilidad en y entre los campos disciplinarios (Clarke, et al., \& Jarvis, 2012).

Esperamos, finalmente, contribuir a pensar qué ocurre en la academia, escapando al conformismo y a la autocomplacencia. Se trata de aportar insumos que, mediante la investigación y la escritura, nos ayuden a sacudirnos de la pasividad, nos permita construir espacios locales de autodefinición y tomar la palabra sobre nosotros mismos, con una profunda conciencia de sus efectos y posibilidades (De Cer- 
teau, 1995). En definitiva, se trata de responsabilizarnos, como comunidad académica, de nuestro futuro en el actual contexto (Jordana, 2013).

\section{Referencias}

Ainsworth, S., \& Hardy, C. (2008). The enterprising self: Unsuitable job for an older worker. Organization, 15(3), 389-405.

Anderson, G. (2008). Mapping academic resistance in the managerial university. Organization, 15(2), 251-270.

Bauman, Z. (1998a). Trabajo, Consumo y Nuevos Pobres. Barcelona: Gedisa.

Bauman, Z. (1998b). Globalizacioón . Buenos Aires : Fondo de Cultura Economica.

Beck, U. (2002). La sociedad del riesgo global. Madrid: Siglo XXI.

Boltanski, L., \& Chiapello, E. (1999). El nuevo espiritu del capitalismo. París: Gallimard.

Brown, A. D. (2006). A narrative approach to collective identities. Journal of Management Studies, 43(4), 731-753

Brunner, J. J. (1999). La educación superior frente a los desafíos del futuro. Discurso de inauguración del año académico. Universidad de Valparaíso, Valparaíso.

Callinicos, A. (2006). Universities in a neoliberal world. London: Bookmarks.

Chandler, J., Barry, J., \& Clark, H. (2002). Stressing academe: The wear and tear of New Public Managment. Human Relations, 55(9) 1051-1069.

Clarke, C., Knights, D., \& Jarvis, C. (2012). Labour of Love? Academics in Business Schools. Scandinavian Journal of Managment, 28 (1), 5-15.

Coffey, A., \& Atkinson, P. (2003). Encontrar el sentido a los datos cualitativos. Estrategias complementarias de investigación. Medellín: Editorial Universidad de Antioquia.

De Certeau, M. (1995). La toma de la palabra y otros escritos políticos. México: Universidad Iberoamericana (UAI).

Delamont, S. (1992). Fielwork in educational settings: Methods, pitfalls and perspectives. Londres: Falmer.
Denzin, N. (2001). The reflexive interview and a performative social science. Qualitative Research, 1(1), 23-46.

Denzin, N., \& Lincoln, Y. (2003). Strategies of qualitative inquiry. Thousand Oaks: Sage.

Du Gay, P. (2007). Organizing Identity. London : Sage.

Dubar, C. (1991). La socialisation construction des identités sociales et profesionelless. París: Armand Collin.

Dubar, C. (2000). La crise del identités, l'interpretation d'une mutation. París: Presses Universitaires de France.

Edwards, D. (1999). Emotion discourse. Culture EF Psychology, 5(3), 271-291.

Fardella, C. (2013). Resistencias en torno a la institucionalizacion del modelo Neoliberal en educacion: el caso de los docente en Chile. Psicoperspectivas: Individuo y Sociedad, 12(2), 83-92.

Flick, U. (2004). Introducción a la investigación cualitativa. Madrid, España: Morata.

Foucault, M. (2010). El coraje de la verdad. El gobierno de sí y de los otros II. Curso en el Collège de France (1983-1984). Buenos Aires: Fondo de Cultura Económica.

Gill, R. (2009). Breaking the silence: The hidden injuries of neo-liberal academia. En R. Flood, \& R. Gill, Secrecy and silence in the research process: Feminist Reflections. London: Routledge.

Gorz, A. (1997). Metamorfosis del trabajo. Busqueda de sentido. Crítica de la razón económica. Madrid: Editorial Sistema.

Gubrium, J., \& Holstein, J. (1998). Narrative practice and the coherence of personal stories. The Sociological Quarterly, 39(1), 163-87.

Harding N, Ford J and Gough B (2010) Accounting for ourselves: Are academics exploited workers? Critical Perpsectives on Accounting 21: 159-168.

Holstein, J., \& Gubrium, J. (1995). The active interview. London: Sage.

Ibarra, E. (2002). Capitalismo académico y globalización: la universidad reinventada. Revista de la Educaion Superior, 30(1), 147-154.

Íñiguez, L. (2001). Identidad: de lo personal a lo social. Un recorrido conceptual. En E. Crespo, La constitución social de la subjetividad. Madrid: Catarata.

Jack, G., \& Lorbiecki, A. (2007). National identity, globalization and the discursive construction of 
organizational identity. British Journal of Management, 8, S79—S94

Jarvis, \& Pratt. (2006). Bringing it all back home: the extensi cation and 'over owing' of work. The case of San Francisco's new media households. Geoforum 37(3), 331-339.

Jordana, E. (2013). Cuando nos quedamos solos: resistir en la incertidumbre. Prácticas de emancipación y autonomía. Athenea Digital, 13(1), 43-57.

Keenoy, T. (2003) The discursive constructions of performing professionals. In: Koot W, Leisink W and Verweel P (eds) Organizational Relationships in the Networking Age. Northampton,MA: Edward Elgar, 137-158.

Knights, D., \& Willmott, H. (2007). Poder y subjetividad en el trabajo. En C. Fernández, Vigilar y organizar (pp. 27-68). Madrid: Siglo XXI.

Levin, J., \& Shaker, G. (2011). The hibrid and dualistic identity of full-time non-tenure-track faculty. American Behavioral Scientist, 55(11), 1461-1484.

Mancebo, D. (2010). Trabalho docente na educação superior brasileira: mercantilização das relações e heteronomia acadêmica. Revista Portuguesa de Educação, 23(2), 73-91.

Medá, D. (1998). El trabajo: un valor en peligro de extinción. España: Gedisa.

Potter, J., \& Wetherell, M. (1987). Discourse and Social Psychology. London: Sage.

Rancière, J. (2008). El espectador emancipado. Pontevedra: Ellago.

Sachica, A. (2005). El docente universitario y la significacion de su identidad profesional. (Informe de Investigacion). Recuperado de http://intellectum.unisabana.edu.co/bitstream/handle/10818/3257/132035. pdf? sequence $=1 \&$ is Allowed $=y$

Sennett, R. (1998). La corrosión del carácter: las consecuencias personales del trabajo en el nuevo capitalismo. España: Anagrama.

Sisto, V. (2005). Flexibilizacion laboral de la docencia universitaria y la gest(ac)ión de la universidad sin órganos. Un analisis desde la subjetividad laboral del docente en condiciones de precariedad. En P.
Gentili \& B. Levy, Espacio público y privatización del conocimiento. Estudios sobre politicas universitarias en América Latina (pp. 523-574). Buenos Aires: Clacso Libros.

Sisto, V., \& Fardella, C. (2009). Control Narrativo y gubernamentalidad. La producción de coherencia en las narrativas identitarias de profesionales chilenos adultos jóvenes en condiciones de flexibilización labora. FQS, 10(2).

Slaughter, S., \& Leslie, L. (1997). Academic capitalism. Politics, policies and the entrepreneurial university. Baltimore: Johns Hopkins University Press.

Slaughter, S., \& Leslie, L. (2001). Expanding and elaborating the concept of academic capitalism. Organization, 2(8), 154-161.

Slaughter, S., \& Rhoades, G. (2004). Academic capitalism and the new economy: Markets, state and higher education. Baltimore: Johns Hopkins University Press.

Smith, B., \& Sparkes, A. (2008). Contrasting perspectives on narrating selves and identities. Qualitative Research, 8(5), 5-35.

Soto, A., \& Gaete. (2013). Tensiones en la construcción identitaria individualizada en el trabajo flexible. Universitas Psychologica, 12(4), 1167-1180.

Vygotski, L. (1979). El desarrollo de los procesos psicológicos superiores. Buenos Aires: Girjalbo.

Wetherell, M. (2007). A step too far: Discursive psychology, linguistic ethnography and questions of identity. Journal of Sociolinguistics, 11(5), 661-681. doi:10.1111/j.1467-9841.2007.00345.x

Wetherell, M., \& Potter, J. (1998). El análisis del discurso y la identificación de los repertorios interpretativos. En A. Gordo, \& J. Linaza, Psicología, discurso y poder: metodologías cualitativas, perspectivas críticas (pp. 63-78). Madrid: Visor

Worthington, F., \& Hodgson, J. (2005). Academic labour and the politics of quality in higher

education: A critical evaluation of the conditions of possibility of resistance. Critical Quarterly,

47, 1/2 96-110. Ybema S, Keenoy T, Oswick C et al. (2009) Articulating identities. Human Relations 62(3): 299-322. 